\section{Therapeutic Influences of Plants in Hospital Rooms on Surgical Recovery}

\author{
Seong-Hyun Park ${ }^{1}$ and Richard H. Mattson \\ Department of Horticulture, Forestry and Recreation Resources, Kansas \\ State University, 2021 Throckmorton Plant Science Center, Manhattan,
} KS 66506

Additional index words. horticultural therapy, hospital plant environments, human issues in horticulture, people-plant interaction, thyroidectomy surgical recovery

\begin{abstract}
Medical and psychological measurements of surgical patients were tested to determine the influence of plants and flowers within hospital rooms. Eighty female patients recovering from a thyroidectomy were randomly assigned to either control or plant rooms. Patients in the plant room viewed 12 foliage and flowering plants during their postoperative recovery periods. Data collected for each patient included length of hospitalization, analgesics used for postoperative pain control, vital signs, ratings of pain intensity, pain distress, anxiety and fatigue, the State-Trait Anxiety Inventory Form Y-1, the Environmental Assessment Scale, and the Patient's Room Satisfaction Questionnaire. Patients in hospital rooms with plants and flowers had significantly shorter hospitalizations, fewer intakes of analgesics, lower ratings of pain, anxiety, and fatigue, and more positive feelings and higher satisfaction about their rooms when compared with patients in the control group. Findings of this research suggest the therapeutic value of plants in the hospital environment as an effective complementary medicine for surgical patients.
\end{abstract}

Surgery is a threatening experience with multiple stressful components such as physical pain and discomfort, worries about illness, isolation from family and friends, fear of medical procedures, and lack of familiarity with medical personnel, hospital equipment, and the sterile hospital environment. Numerous studies suggested that greater stress or anxiety associated with surgical experience is typically related to more severe postoperative pain and a slower and more complicated postoperative recovery (Cohen and Williamson, 1991; Johnston and Wallace, 1990; Mathews and Ridgeway, 1981). Some of the postoperative problems related to stress can be mediated through intakes of anesthetics and analgesics; however, these drugs have side effects, which can produce postoperative physiological problems (e.g., vomiting, headaches, nausea, and pain at the incision site), drug dependency, and even be fatal if not properly administered (Abbott and Abbott, 1995; Coniam and Diamond, 1994). Therefore, it would be useful to develop nonpharmacological approaches to improving the patient experiences with pain and stress during hospitalization.

To promote the speed of postoperative recovery and to improve the quality of life during hospitalizations, it is important to provide patients with not only the best treatment possible, but also to remove such

Received for publication 22 Jan. 2008. Accepted for publication 3 June 2008 .

We acknowledge Sun-Tae Park and the medical staff for valuable assistance with this project and James Higgins at Kansas State University for statistical advice.

${ }^{1}$ To whom reprint requests should be addressed; e-mail hyunipark@gmail.com. sources of stress and to counter them with positive distractions. The viewing of nature and/or plants has been considered an effective positive distraction, which may provide ample involuntary attention, increase positive feelings, block or reduce worrisome thoughts, and promote restoration from stress (Ulrich, 1992). Researchers who have assessed the impact of nature/plants on human health have suggested that nature and plant experiences are positively associated with human physical (Chang and Chen, 2005; Coleman and Mattson, 1995; Ulrich et al., 1991), psychological (Kaplan, 2001; Kaplan and Kaplan, 1995), emotional (Adachi et al., 2000; Ulrich, 1981; Ulrich et al., 1991), and cognitive health (Cimprich, 1993; Hartig et al., 1991; Tennessen and Cimprich, 1995). In addition, viewing nature/plants is linked to pain reduction, less need for analgesics, and fast recovery from surgery (Diette et al., 2003; Park et al., 2004; Ulrich, 1984).

Clinical trials concerning the health benefits of viewing indoor plants on stress and recovery of surgical patients within a hospital setting do not exist. This investigation determined if exposing surgical patients to plants influences stress reduction and recovery from surgery using various medical and psychological measurements.

Subjects. The sample consisted exclusively of patients who had undergone thyroidectomy surgery, which is a comparatively standardized medical procedure with similar postoperative management in the uncomplicated cases. Eighty female patients (mean age, $36.2 \pm 10$ years) were studied from July 2005 to Jan. 2006 in an 809-bed suburban

\section{Materials and Methods}

university-affiliated hospital in Korea. Human research protocols for this study were approved by the Institution Review Boards of both the academic and hospital setting. Patients were informed that their medical history and current medical records would be reviewed and each signed an informed consent form. Patients were randomly assigned to either control or plant rooms (Fig. 1) as they became available. Equal numbers of single and six-patient rooms were used for two treatments. The rooms, which were located on the same floor and the same side of the building, were identical except for the presence or absence of plants. Patient views from the hospital windows were only of the sky with no presence of trees or other buildings. Patients in the plant group were allowed to view plants during their recovery periods after surgery until discharge. Excluded from the study were patients who were younger than 19 years or older than 60 years and those who reported a chronic (e.g., diabetes or high blood pressure) or current acute (e.g., upper respiratory infection) health problem, a history of psychiatric problems (e.g., depression or anxiety), or uncorrected hearing or visual impairments. All were in good health before surgical treatment.

Measurements. Data collected included the length of hospitalization, analgesics used for postoperative pain control, vital signs, ratings of pain intensity, pain distress, anxiety and fatigue (PPAF), the State-Trait Anxiety Inventory Form Y-1 (STAI-Y1), the Environmental Assessment Scale (EAS), and the Patient's Room Satisfaction Questionnaire (PRSQ).

Outcome data of length of hospitalization, postoperative analgesic intakes, and vital signs were extracted from patient charts. Length of hospitalization was defined as days from surgery to discharge. Postoperative analgesics were classified as weak, moderate, or strong on the basis of the drug and amount and whether it was administered orally or by injection. The weak category was dominated by small doses of talniflumate, a nonsteroidal anti-inflammatory drug (NSAID), and the moderate category included large doses of talniflumate up to $1480 \mathrm{mg} \cdot \mathrm{d}^{-1}$. In the strong category, injections of ketorolac tromethamine (NSAID) or combinations with talniflumate doses were used. Vital signs recorded were systolic and diastolic blood pressures (millimeters of mercury), body temperature $\left({ }^{\circ} \mathrm{C}\right)$, heart rate (beats per minute), and respiratory rates (breaths per minute). Vital signs were defined as the average of three readings taken per day. All measurements were taken using standard, noninvasive technology and were recorded on patient charts.

Levels of the PPAF were measured using a 101-point numerical rating scale (NRS101). The validity of the NRS-101 and its sensitivity to treatment effects have been well documented (Jensen and Karoly, 1992; Jensen et al., 1986). The NRS-101 (rating from 0 to 100 ) is reported to have several advantages over the other rating scales and to be more sensitive to treatment effect than the 

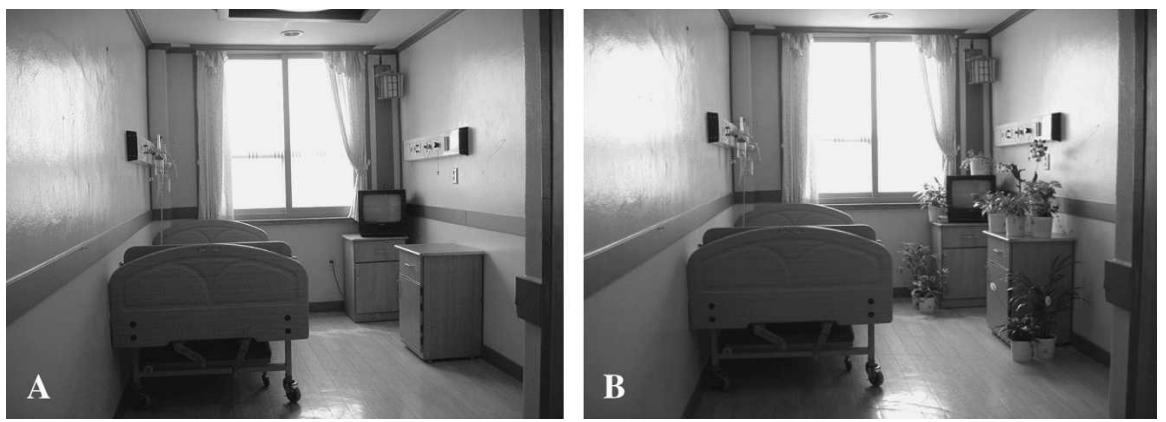

Fig. 1. Photographs of the two hospital room treatments. (A) No plants and (B) foliage and flowering plants. The rooms, which were located on the same floor and the same side of the building, were identical except for the presence or absence of plants. The combinations of plants used in each room were identical. Room B contained single plants of arrowhead vine, cretan brake fern, variegated vinca, and yellow star jasmine arranged with two plants each of dendrobium, peace lily, golden pothos, and kentia palm.

NRS-11 (rating from 0 to 10 ) as a result of a large number of response categories (Jensen et al., 1986).

The STAI-Y (Spielberger, 1983) is comprised of a self-report measurement of anxiety and has been used extensively in research and clinical practice. The STAI consists of two scales. The STAI-Y1 scale includes 20 statements intended to measure transitory feelings of tension, nervousness, apprehension, and worry, whereas the STAI-Y2 section evaluates the stable personality trait of anxiety proneness. This study used the STAI-Y1 because it was designed to measure changes in anxiety resulting from situational stress. Psychometric properties of the STAI$\mathrm{Y}$ and studies supporting its construct validity and reliability are presented in the STAI-Y manual (Spielberger, 1983).

To measure patients' feelings in response to their hospital room, the modified EAS was used (Rohles and Milliken, 1981). The EAS consists of 13 adjective pair semantic differential scales. The EAS has been used in previous studies to evaluate the affective characteristics of the environment and various features it contains (Laviana, 1985; Laviana et al., 1983).

To assess patient satisfaction with the hospital room, patients were asked to complete the PRSQ, which indicated three positive and three negative qualities of their room environments. Patients were further asked about their willingness to return to their room during any future hospitalization. Space was provided so the patient could add comments.

Procedures. A meeting with the hospital doctors and nurses was held before the beginning of the research. Research objectives were explained that included their need to treat patients similarly. In addition, nurses were assigned to help patients in both the control and plant rooms and were urged not to be influenced by the content of the rooms. Patients were hospitalized a day before surgery to be given preparatory information about surgical procedures. On the day of admission, after obtaining the informed consent agreement from the patient and after health screening, patients completed the
PPAF, STAI-Y1, and EAS in the hospital room.

For the plant room, 12 potted foliage and flowering plants with sterile, soilless potting mix were placed in the hospital room after patients left the room for surgery. Plants selected for the hospital rooms were dendrobium (Dendrobium phalaenopsis), peace lily (Spathiphyllum 'Starlight'), golden pothos (Epipremnum aureum), kentia palm (Howea forsteriana), arrowhead vine (Syngonium podophyllum 'Albolineatum'), cretan brake fern (Pteris cretica 'Albolineata'), variegated vinca (Vinca minor 'Illumination'), and yellow star jasmine (Trachelospermum asiaticum 'Ougonnishiki'). Single plants of four species were arranged with two plants each of dendrobium, peace lily, golden pothos, and kentia palm. Plant selection was based on space consideration, sunlight accessibility, requirements of temperature and humidity, low maintenance, and visual appeal with various colors, sizes, patterns, and shapes. Plants were added or removed as needed to accomplish each treatment. The combinations of plants used in each room were identical. Plants were grown in selfwatering containers, and patients were not disturbed by plant maintenance during hospitalizations. Patients were not told of the study objectives or how to interact with the plants. Control rooms contained no plant materials.

During the recovery period, the PPAF and the STAI-Y1 were administered on the first, third, and fifth days after surgery. The second trial of the EAS and the initial trial of the PRSQ were administered on the last day of hospitalizations. All measurements were taken by the researcher except demographics, analgesic intakes, and vital signs, which were recorded by medical staff.

Data analyses. Analysis of covariance (ANCOVA) (Littell et al., 2006) using SAS PROC GLM (version 8.0; SAS Institute, Cary, NC) was completed for data of hospitalization and the EAS to test for differences between groups. Age was used as the covariate for ANCOVA. A repeated-measures ANCOVA (Littell et al., 2006) using SAS
PROC MIXED was done for data of vital signs and the PPAF and the STAI-Y1 to test for differences between groups at each day of hospitalization and to compare trends for groups over postoperative recovery periods. Because of the differences in age and preoperative score, the patient's age and preoperative score were used as the covariates for a repeated-measures ANCOVA. The exact $\chi^{2}$ test (Higgins, 2004) using SAS PROC FREQ was performed for analgesic intake to test for differences between groups at the day of surgery and first day after surgery, Days 2 through 3 after surgery, and Days 4 through 5 after surgery. Alpha level was set at 0.05 .

\section{Results and Discussion}

The mean length of hospitalizations for the plant group was $6.08 \mathrm{~d}$ and was significantly different from that of the control group at $6.39 \mathrm{~d}$. These records provide evidence that patients who viewed plants had significantly shorter hospitalizations than those patients without plants $(P=0.034)$. Analgesic intake (Fig. 2) was significantly different for the plant group compared with the control group at Days 4 through 5 after surgery $(P=0.04)$. Patients exposed to plants were less frequently given weak and moderate analgesics compared with patients in the control group. No significant day-by-group interactions and no significant group differences were found for vital signs during the recovery periods.

As shown in Table 1, the means are presented for preoperative and postoperative ratings of the PPAF and the STAI-Y1. Among the PPAF outcomes, significant day-by-group interactions were noted for self-rated pain intensity, pain distress, and fatigue $(P=0.045, P=0.04, P=0.048$, respectively). Levels of pain intensity, pain distress, and fatigue remarkably decreased for most patients in both groups throughout the recovery periods. Pain intensity was significantly lower for those patients exposed to plants compared with no plants on the third and fifth days after surgery $(P=0.012, P=$ 0.01 , respectively). The dynamic changes of pain distress were parallel with that of pain intensity and were consistently lower than the pain intensity ratings. Pain distress was significantly lower for those patients exposed to plants compared with no plants on the fifth day after surgery $(P=0.002)$. Comparing plant group patients with control group patients, fatigue was significantly lower on the fifth day after surgery $(P=0.01)$. No significant day-by-group interactions were reported and significant group differences were found for self-rated anxiety and the STAI-Y1. Patients in the plant group had significantly lower anxiety than patients in the control group during the recovery periods $(P=0.01)$. Patients in the plant group were characterized by significantly lower levels of state anxiety and tension than patients in the control group during the recovery periods $(P=0.01)$. This result was consistent with that of anxiety NRS-101 ratings. 


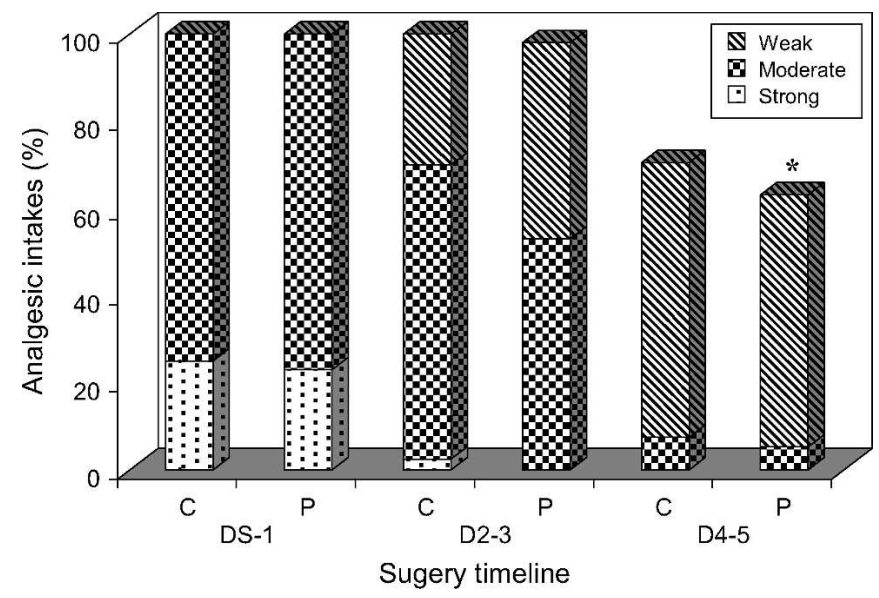

Fig. 2. Comparisons of control (C) and plant (P) groups (40 female patients undergoing thyroidectomy per group) in postoperative analgesic intakes. Analgesics were classified as weak, moderate, or strong on the basis of the drug an amount and whether it was administered orally or by injection. DS-1, D2-3, and D4-5 indicate the day of surgery and first day after surgery, Days 2 through 3 after surgery, and Days 4 through 5 after surgery, respectively. Some of the patients did not receive analgesics on D4-5, and a few had left the hospital on D5. An asterisk indicates significance at $P<0.05$ (compared with control).

Table 1. Pain intensity, pain distress, anxiety and fatigue (PPAF) ${ }^{\mathrm{z}}$, and State-Trait Anxiety Inventory Form Y-1 (STAI-Y1)y mean ratings for control $(\mathrm{C})$ and plant $(\mathrm{P})$ groups of 40 female patients undergoing thyroidectomy per group.

\begin{tabular}{lccccccccccc}
\hline & \multicolumn{2}{c}{ Pain intensity $^{\mathrm{z}}$} & \multicolumn{2}{c}{ Pain distress $^{\mathrm{z}}$} & \multicolumn{2}{c}{ Anxiety $^{\mathrm{z}}$} & \multicolumn{2}{c}{ Fatigue $^{\mathrm{z}}$} & \multicolumn{2}{c}{ STAI-Y1 $^{\mathrm{y}}$} \\
& \multicolumn{2}{c}{$(0-100$} & scale $)$ & \multicolumn{2}{c}{$(0-100$} & scale $)$ & \multicolumn{2}{c}{$(0-100$ scale $)$} & \multicolumn{2}{c}{$(0-100$ scale $)$} & \multicolumn{2}{c}{ (1-4 scale $)$} \\
\hline Timeline $^{\mathrm{x}}$ & $\mathrm{C}$ & $\mathrm{P}$ & $\mathrm{C}$ & $\mathrm{P}$ & $\mathrm{C}$ & $\mathrm{P}$ & $\mathrm{C}$ & $\mathrm{P}$ & $\mathrm{C}$ & $\mathrm{P}$ \\
BS $^{\mathrm{w}}$ & 3.77 & 6.89 & 2.74 & 6.14 & 66.05 & 67.16 & 43.35 & 40.77 & 47.14 & 49.41 \\
D1 & 90.75 & 88.35 & 89.23 & 87.80 & 54.88 & $51.82^{*}$ & 85.36 & 84.21 & 43.85 & $41.89^{*}$ \\
D3 & 73.88 & $67.60^{*}$ & 69.48 & 65.18 & 27.26 & $24.32^{*}$ & 48.73 & 43.09 & 35.20 & $33.24^{*}$ \\
D5 & 49.37 & $42.49^{*}$ & 41.36 & $34.30^{*}$ & 9.61 & $8.00^{*}$ & 27.50 & $19.26^{*}$ & 27.50 & $26.03^{*}$ \\
\hline
\end{tabular}

${ }^{\mathrm{Z} P P A F}$ is based on a 101-point numerical rating scale (Pain intensity: $0=$ no pain, $100=$ pain as bad as it could be; Pain distress: $0=$ comfortable, $100=$ excruciating; Anxiety: $0=$ complete relaxation, $100=$ the worst feelings of anxiety; Fatigue: $0=$ no fatigue, $100=$ worst fatigue).

y Twenty items ( 10 anxiety-present items and 10 anxiety-absent items) were given a weighted score of 1 to $4(1=$ not at all, $2=$ somewhat, $3=$ moderately, $4=$ very much $)$. A rating of 4 indicates the presence of a high level of anxiety for 10 anxiety-present items and the anxiety-absent items for which the scoring weights are reversed. Scores range from 20 to 80 . A lower value indicates less anxiety.

${ }^{\mathrm{x}} \mathrm{BS}=$ before surgery; D1 = first day after surgery; D3 = third day after surgery; D5 = fifth day after surgery. ${ }^{\mathrm{w}} \mathrm{BS}$ (preoperative scores) used as the covariates. Means at D1, D3, and D5 for the PPAF and the STAI-Y1 are adjusted for differences from BS.

$* P<0.05$ (compared with control).

Table 2. Mean changes in the 13 items of the Environmental Assessment Scale (EAS; Rohles and Milliken, 1981) self-rated by patients with thyroidectomy ( 40 female patients per group) before surgery and at the last day of hospitalization in responses to viewing 'foliage and flowering plants' and 'no plants' during recovery.

\begin{tabular}{|c|c|c|c|c|c|c|}
\hline \multirow[b]{3}{*}{ EAS items } & \multicolumn{3}{|c|}{ Control group } & \multicolumn{3}{|c|}{ Plants group } \\
\hline & Pre & Post & Post-Pre $^{z}$ & Pre & Post & Post-Pre \\
\hline & \multicolumn{6}{|c|}{$(1-9 \text { scale })^{y}$} \\
\hline Satisfying-annoying & 5.02 & 5.03 & 0.01 & 5.48 & 6.16 & $0.68^{*}$ \\
\hline Clean-dirty & 4.94 & 4.83 & -0.11 & 4.98 & 5.12 & 0.14 \\
\hline Relaxing-stressing & 4.97 & 4.91 & -0.06 & 5.17 & 5.84 & $0.67 * *$ \\
\hline Comfortable-uncomfortable & 5.13 & 5.09 & -0.04 & 5.19 & 5.61 & $0.42 *$ \\
\hline Colorful-drab & 4.26 & 4.18 & -0.08 & 4.32 & 6.46 & $2.14 * *$ \\
\hline Happy-sad & 4.56 & 4.45 & -0.11 & 4.98 & 5.42 & $0.44 *$ \\
\hline $\begin{array}{l}\text { Pleasant smell-unpleasant } \\
\text { smell }\end{array}$ & 4.52 & 4.45 & -0.07 & 4.58 & 5.08 & $0.50 *$ \\
\hline Bright-dull & 6.81 & 6.87 & 0.06 & 6.94 & 6.97 & 0.03 \\
\hline Spacious-crowded & 5.40 & 5.24 & -0.16 & 5.42 & 5.14 & -0.28 \\
\hline Calming-irritating & 6.32 & 6.07 & -0.25 & 5.53 & 6.01 & $0.48^{* *}$ \\
\hline Warm-cool & 4.90 & 4.87 & -0.03 & 4.85 & 4.95 & 0.10 \\
\hline Attractive-unattractive & 4.19 & 4.00 & -0.19 & 4.86 & 5.28 & $0.42 *$ \\
\hline Quiet-noisy & 6.00 & 5.33 & -0.67 & 5.99 & 5.16 & -0.83 \\
\hline
\end{tabular}

${ }^{\mathrm{z}}$ Differences in EAS scores of pretest (self-rated before surgery) and posttest (self-rated at the last day of hospitalization) were computed.

${ }^{\mathrm{y}} 1=$ least desirable, $9=$ most desirable.

*, **Significance at $P<0.05$ or 0.01 , respectively (compared with control).
Significant differences between the EAS responses of the two groups were found for the eight items (Table 2). The EAS responses to plants indicated that patients during the recovery periods reported their rooms had a pleasant smell and were more satisfying, relaxing, comfortable, colorful, happy, calming, and attractive compared with those in the control rooms.

Results of the PRSQ showed the majority of patients in the plant group indicated that plants were the most positive qualities of their rooms $(95 \%)$, whereas patients in the control group reported watching television as the most favorable aspect of their rooms $(85 \%)$. The next categories of positive qualities regarding the hospital room included large windows $(57 \%)$, sunshine $(48 \%)$, and appropriate temperature $(37 \%)$ for the plant group, whereas appropriate temperature $(55 \%)$ and large windows (40\%) were highly favored for the control group. Regarding negative qualities of the hospital room, patients in the control and plant groups had similar negative comments concerning toilet facilities, insufficient space, and hospital environments. Patients were further asked about their willingness to return to their room during any future hospitalization. Ninety-three percent of patients in the plant group responded positively, whereas $70 \%$ of patients in the control group reported a willingness to return.

Voluntary comments of patients were collected from nurses and from the PRSQ. Many patients in the plant group stated that plants helped them relax or feel less anxious, and some believed that plants had diminished their pain. Patients also reported that plants in their rooms created a positive image of the hospital and of the medical staff who were sensitive to the healing potential of "nearby nature."

Results indicate that female patients who were recovering from thyroidectomy in hospital rooms containing plants had significantly shorter hospitalizations, less need for analgesics, lower ratings of pain, anxiety, and fatigue, and more positive feelings and higher satisfaction about their hospital rooms compared with patients without plants. This study extends earlier research, which showed male and female surgical patients with a window view of trees had shorter hospital stays, fewer negative comments in nurses' notes, and fewer intakes of analgesics than did patients with a window view of a brick wall (Ulrich, 1984).

Interior hospital spaces can be made healthier with the presence of living plants. Previous research has indicated that indoor plants reduce sick-building syndrome by removing pollutants (Darlington et al., 2001; Wolverton et al., 1989; Wood et al., 2002), increase relative humidity up to human comfort level (Lohr, 1992; Wolverton and Wolverton, 1993), and improve indoor air quality by reducing the quantity of mold spores and airborne microorganisms (Wolverton and Wolverton, 1993).

Colorful fresh cut flowers and blooming or green plants could be a complementary 
medicine for patients. If properly maintained, indoor plants can provide a great opportunity for patients to experience nature in all seasons when outdoor scenery could not provide this benefit. Furthermore, plants provide meaningful therapeutic contact, especially for patients spending much of their time indoors while recovering from painful surgery.

Findings from this study may not be applied to the immediate environments of severely immunocompromised and intensive care unit patients. However, this study provides strong evidence that contact with plants is directly beneficial to patients' health. This nonpharmacological complementary approach is medically beneficial and clearly cost-effective not only to patients, but also to health insurance companies by reducing the costs of hospitalization and analgesic consumption. Healthcare professionals and hospital administrators need to consider the use of plants and flowers to enhance healing environments for patients.

\section{Literature Cited}

Abbott, J. and P. Abbott. 1995. Psychological and cardiovascular predictors of anesthesia induction, operative and postoperative complications in minor gynecological surgery. Br. J. Clin. Psychol. 34:613-625.

Adachi, M., C.L.E. Rode, and A.D. Kendle. 2000. Effects of floral and foliage displays on human emotions. HortTechnology 10:59-63.

Chang, C. and P. Chen. 2005. Human response to window views and indoor plants in the workplace. HortScience 40:1354-1359.

Cimprich, B. 1993. Development of an intervention to restore attention in cancer patients. Cancer Nurs. 16:83-92.

Cohen, S. and G. Williamson. 1991. Stress and infectious disease in humans. Psychol. Bull. 109:5-24.

Coleman, C.K. and R.H. Mattson. 1995. Influences of foliage plants of human stress during thermal biofeedback training. HortTechnology 5:137140.
Coniam, S.W. and A.W. Diamond. 1994. Practical pain management. Oxford Univ. Press, Oxford, UK.

Darlington, A.B., J.F. Dat, and M.A. Dixon. 2001 The biofiltration of indoor air: Air flux and temperature influences the removal of toluene, ethylbenzene, and xylene. Environ. Sci. Technol. 35:240-246.

Diette, G., E. Haponik, and H. Rubin. 2003. Distraction therapy with nature sights and sounds reduces pain during flexible bronchoscopy. Chest 12:941-948.

Hartig, T.A., M. Mang, and G.W. Evans. 1991. Restorative effects of natural environment experiences. Environ. Behav. 23:3-27.

Higgins, J.J. 2004. Introduction to modern nonparametric statistics. Brooks/Cole, Pacific Grove, CA.

Jensen, M.P. and P. Karoly. 1992. Self-report scales and procedures for assessing pain in adults, p. 193-213. In: Truk, D.C. and R. Melzack (eds.). Handbook of pain assessment. Guilford Press, New York, NY.

Jensen, M.P., P. Karoly, and S. Braver. 1986. The measurement of clinical pain intensity: A comparison of six methods. Pain 27:117-126.

Johnston, M. and L. Wallace. 1990. Stress and medical procedures. Oxford University Press, Oxford, UK.

Kaplan, R. 2001. The nature of the view from home: Psychological benefits. Environ. Behav. 33:507-542.

Kaplan, R. and S. Kaplan. 1995. The experience of nature: A psychological perspective. Ulrich's, Ann Arbor, MI.

Laviana, J.E. 1985. Assessing the impact of plants in the simulated office environment: A human factors approach, Kansas State University, Manhattan. PhD Diss.

Laviana, J.E., R.H. Mattson, and F.H. Rohles. 1983. Plants as enhancers of the indoor environment. Proc. 27th Ann. Mtg. Human Factors Soc., Norfolk, VA. p. 738-741.

Littell, R.C., G.A. Milliken, W.W. Stroup, and R.D. Wolfinger. 2006. SAS for mixed models. SAS Institute, Cary, NC.

Lohr, V.I. 1992. The contribution of interior plants to relative humidity in an office, p. 117-119. In: Relf, P.D. (ed.). The role of horticulture in human well-being and social development. Timber Press, Portland, OR.

Mathews, A. and V. Ridgeway. 1981. Personality and surgical recovery: A review. Brit. J. Clin. Psychol. 20:243-260.

Park, S., R.H. Mattson, and E. Kim. 2004. Pain tolerance effects of ornamental plants in a simulated hospital patient room. Acta Hort. 639:241-247.

Rohles, F.H. and G.A. Milliken. 1981. A scaling procedure for environmental research. Proc. 25th Ann. Mtg. Human Factor Soc., Rochester, NY. p. 472-475.

Spielberger, C.D. 1983. Manual for the state-trait anxiety inventory (STAI) (Form Y: Self-evaluation questionnaire). Mind Garden, Redwood City, CA.

Tennessen, C.M. and B. Cimprich. 1995. Views to nature: Effects on attention. J. Environ. Psychol. 15:77-85.

Ulrich, R.S. 1981. Natural versus urban scenes: Some psycho-physiological effects. Environ. Behav. 13:523-556.

Ulrich, R.S. 1984. View through a window may influence recovery from surgery. Science 224:420-421.

Ulrich, R.S. 1992. How design impacts wellness. Healthc. Forum J. 35:20-25.

Ulrich, R.S., R.F. Simons, B.D. Losito, E. Fiorito, M.A. Miles, and M. Zelson. 1991. Stress recovery during exposure to natural and urban environment. J. Environ. Psychol. 11:201230.

Wolverton, B.C., A. Johnson, and K. Bounds. 1989. Interior landscape plants for indoor air pollution abatement: Final report. Natl. Aeronautics Space Admin., John C. Stennis Space Center, MS

Wolverton, B.C. and J. Wolverton. 1993. Interior plants: Their influence on airborne microbes and relative humidity levels inside energyefficient buildings. Res. Rpt. WES/100/0593-011, Wolverton Environmental Service, Picayune, MS.

Wood, R.A., R.L. Orwell, J. Tarran, F. Torpy, and M. Burchett. 2002. Potted plant/growth media interactions and capacities for removal of volatiles from indoor air. J. Hort. Sci. Biotechnol. 77:120-129. 